\title{
Co-delivery of Cisplatin(IV) and Capecitabine as an Effective and Non-toxic Cancer Treatment
}

\author{
Xiao Xiao ${ }^{1,2 t}$, Ting Wang ${ }^{3 t}$, Leijiao Li $^{4 *}$, Zhongli Zhu4, Weina Zhang ${ }^{5}$, Guihua Cui ${ }^{1,2 *}$ and \\ Wenliang $\mathrm{Li}^{1,2 *}$
}

${ }^{1}$ School of Pharmacy, Jilin Medical University, Jilin, China, ${ }^{2}$ Center for Biomaterials, Jilin Medical University, Jilin, China, ${ }^{3}$ Department of the Gastrointestinal Surgery, The First Hospital of Jilin University, Changchun, China, ${ }^{4}$ Jilin Provincial Science and Technology Innovation Center of Optical Materials and Chemistry, School of Chemistry and Environmental Engineering, Changchun University of Science and Technology, Changchun, China, ${ }^{5}$ Common Subjects Department, Shangqiu Medical College, Henan, China

OPEN ACCESS

Edited by:

Wei Tao,

Harvard Medical School,

United States

Reviewed by:

Jinshan Guo,

Harvard University, United States

Xiaoding $\mathrm{Xu}$,

Sun Yat-sen University, China

${ }^{*}$ Correspondence:

Leijiao Li

lileijiao@ciac.ac.cn

Guihua Cui

675053025@qq.com

Wenliang Li

wenliang/@ciac.ac.cn

†These authors have contributed equally to this work

Specialty section:

This article was submitted to

Experimental Pharmacology

and Drug Discovery,

a section of the journal

Frontiers in Pharmacology

Received: 07 December 2018

Accepted: 28 January 2019

Published: 19 February 2019

Citation:

Xiao X, Wang T, Li L, Zhu Z, Zhang W, Cui G and Li W (2019)

Co-delivery of Cisplatin(IV) and Capecitabine as an Effective and Non-toxic Cancer Treatment.

Front. Pharmacol. 10:110.

doi: 10.3389/fphar.2019.00110
A strategy for preparing composite micelles (CM) containing both cisplatin(IV) [CisPt(IV)] prodrug and capecitabine using a co-assembly method is described in this study. The $\mathrm{CM}$ are capable of an effective release of the anticancer drug cisplatin(II) [CisPt(II)] and capecitabine via acid hydrolysis once they are internalized by cancer cells. Moreover, the CM display a synergistic effect in vitro and the combination therapy in the micellar dosage form leads to reduced systemic toxicity and enhanced antitumor efficacy in vivo.

Keywords: co-delivery, cisplatin(IV), capecitabine, cancer treatment, composite micelles

\section{INTRODUCTION}

Utilization of single small molecule anticancer agents in clinical thermotherapy is very rare owing to the rapid development of drug resistance in tumor cells (Di Francesco et al., 2002; Ahmad, 2010). Hence, drug combination is predominantly used in the clinical setting (Joensuu et al., 1998; Feldmann et al., 2007; Woodcock et al., 2011). Combination therapy presents its own set of advantages, related to the improved medication compliance and the enhanced ability to formulate combined drug profiles. From the pharmacokinetic stand point, the positive effects and adverse effects of a combination therapy may be specific to the relative dosages providing a simpler overview compared to single drug profiles. Moreover, the interaction between the individual drugs in a specific combination drug may also provide additional positive effects which may be absent in the individual drug profiles. The active ingredients used in combination drugs rarely exhibit any adverse interactions and are scrupulously reviewed by the Food and Drug Administration (FDA) in the United States (Love et al., 1989; Sitzia and Huggins, 1998). Among the combination chemotherapy regimens, co-administration of capecitabine and platinum-based drugs is the most common.

Platinum-based anticancer agents are one of the most commonly used chemotherapeutic drugs in the treatment of various solid tumors (Lebwohl and Canetta, 1998; Pasettoa et al., 2006; Xiao et al., 2017; Shen et al., 2018). However, almost all platinum drugs possess some inherent and serious side effects which influence drug resistance (Sharma et al., 2005; Windebank and Grisold, 2008). Cisplatin (cis-diamminedichloroplatinum, CDDP) is the first approved platinum drug, which has been used as a standard chemotherapeutic agent for more than 30 years (Weiss and Christian, 1993; Rosenberg and Lippert, 1999). Due to the low concentration of chloride, cisplatin is hydrolyzed inside the cell and is converted to the highly reactive species $\left[\mathrm{Pt}\left(\mathrm{NH}_{3}\right)_{2} \mathrm{Cl}\left(\mathrm{OH}_{2}\right)\right]^{+}$, which creates 1,2-GpG intrastrand adducts within the DNA. The adducts inhibit DNA transcription and replication, ultimately leading to cancer cell apoptosis (Jamieson and Lippard, 1999; 
Boulikas et al., 2007). Nevertheless, severe side effects, including nephrotoxicity, neurotoxicity, ototoxicity and myelosuppression, limit the clinical application of cisplatin. Moreover, the intrinsic and acquired resistance developed by various cancers is another main reason for limiting application of cisplatin (Madias and Harrington, 1978; Ekborn et al., 2000).

Fluorouracil (5-FU) is one of the most widely used medications for the treatment of various cancers, such as colon, esophageal, stomach, pancreatic, breast, and cervical cancers. Unfortunately, 5-FU is distributed to both the healthy and the cancer cells following systemic administration making the drug cytotoxic and leading to death of healthy cells (Arkenau et al., 2003). Capecitabine is an antitumor fluoropyrimidine carbamate, which is very specific only toward cancer cells owing to the activation of tumor-specific enzymes (Ssif et al., 2008).

In comparison to single drug anti-cancer treatment, enhanced tumor therapy efficiency is often observed in patients administered a combination therapy (Joensuu et al., 1998; Feldmann et al., 2007; Woodcock et al., 2011). For example, Xeloda is indicated for the first-line treatment of advanced gastric cancer and is a combination of capecitabine and platinum regimen (DÍaz-Rubio et al., 2002). However, ensuring a correct dosage of a given combination drug in the context of endocytosis within the cell remains a huge challenge in small molecule-based combination therapy. In addition, unfavorable side effects likely accompany the combination of small molecule drugs. To improve the therapeutic efficacy and to reduce the side effects, nanocarriers are used to encapsulate the combination drugs (Duncan, 2003; Kwangjae et al., 2008; Maeda, 2010; Bae and Park, 2011; Tao et al., 2013, 2014, 2016, 2017, 2018; Zhu et al., 2018; Ling et al., 2019). Nanomedicine approach can assure selective accumulation of the drug at tumor sites via the enhanced permeation and retention effect, in turn protecting the drug from premature degradation and blood clearance.

In this work, two polymer-drug conjugates [MPEG- $b$-P(LAco-MCC)-COOH/capecitabine and MPEG- $b$-P(LA-co-MCC)$\mathrm{OH} / \mathrm{CisPt}(\mathrm{IV})]$ were synthesized (Scheme 1). Because of the amphiphilic properties of these polymer-drug conjugates, they were able to be co-assembled into composite micelles (CM) creating a combination therapy drug delivery system (Scheme 2).

The resulting polyprodrug-based combination chemotherapy regimen displays many unique features. Firstly, the relative drug doses of cisplatin(IV) and capecitabine can be easily adjusted by modulating the ratio of PEG-PLA/CisPt(IV). Next, the polymer micelles-based prodrug delivery system provides the active drugs [cisplatin(II) and 5-FU] with double protection. Specifically, both cisplatin(IV) and capecitabine are located in the core of the CM resulting in effective protection mechanism. Additionally, the other protection stems from the prodrug formulation. After a series biotransformation events, cisplatin(IV) and capecitabine get converted to active agents' cisplatin(II) and 5-FU, respectively. Therefore, it is critical for small molecule drug delivery to assure constant levels of the two drugs in the circulation. Importantly, the polymer micelle-based prodrug strategy provides an effective protection for the drugs. Compared to other small moleculebased combination therapies, our method displays significantly lower systemic toxicities. Finally, once the polymeric CM enter the tumor cells, prodrugs cisplatin(IV) and capecitabine will be released by the hydrolysis of PEG-PLA/cisplatin(IV) and PEG-PLA/capecitabine conjugates in the micelles as shown in Scheme 2. Moreover, cisplatin(IV) can be converted to cisplatin(II) under the intracellular reducing conditions (i.e., high concentration of glutathione (GSH) and ascorbic acid). Cisplatin(II) can also become conjugated to basic groups of DNA, in turn killing the tumor cells. Additionally, capecitabine can be converted to 5-FU under the enzymatic catalysis. Specifically, 5 -FU can be converted to fluorouridine triphosphate (FUTP) and fluorodeoxyuridine triphosphate (FdUTP), which are then incorporated into RNA and DNA, respectively, ultimately leading to cell death.

\section{MATERIALS AND METHODS}

\section{Materials}

The polymers MPEG- $b$-P(LA-co-MCC)-COOH and MPEG$b$-P(LA-co-MCC)-OH were synthesized as previously described. N,N'-dicyclohexylcarbodiimide (DCC) and $N$-hydroxybenzotriazole (HOBt) were purchased from SigmaAldrich. CisPt(IV) prodrug was synthesized as reported in our earlier work and capecitabine was purchased from the Zhejiang Haizheng Pharmacy Co. Ltd. All other chemicals and solvents were used without additional purification steps.

\section{General Measurements}

${ }^{1} \mathrm{H}-\mathrm{NMR}$ spectra were measured by a Unity-300 $\mathrm{MHz}$ NMR spectrometer (Bruker) at room temperature. Fourier Transform infrared (FT-IR) spectroscopy was performed using a Bruker Vertex 70 spectrometer. A Quattro Premier XE system (Waters) equipped with an electrospray interface was used for the mass spectroscopy (ESI-MS) assessments. The total platinum (Pt) content in the polymer-Pt(IV) conjugates and in samples obtained from the dialysis bags in drug release experiments was determined by inductively coupled plasma optical emission spectrometer (ICP-OES, iCAP 6300, ThermoScientific, United States). The quantitative determination of trace levels of Pt was measured by ICP-MS (Xseries II, ThermoScientific, United States). Size and size distribution of micelles were determined by dynamic light scattering (DLS) with a vertically polarized He-Ne laser (DAWN EOS, Wyatt Technology, United States). The morphology of the polymer micelles was evaluated by transmission electron microscope (TEM) performed on a JEOL JEM-1011 electron microscope. Particle size and zeta potential measurements were conducted on a Malvern Zetasizer Nano ZS. (Zetasizer Nano ZS is a high performance dual angle particle size and molecular size analyzer that uses DLS combined with "NIBS" optics to enhance the detection of aggregates, as well as small or diluted samples, and poles. Low or high concentration sample).

\section{Synthesis of N-Hydroxy-Succinamide (NHS) Ester of MPEG-b-P(LA-co-MCC)}

MPEG- $b$-P(LA-co-MCC) (0.5 g, $0.0625 \mathrm{mmol})$ was dissolved in $5 \mathrm{~mL}$ of $\mathrm{CH}_{2} \mathrm{Cl}_{2}$ in a flask, to which DCC (128.9 mg, 
A

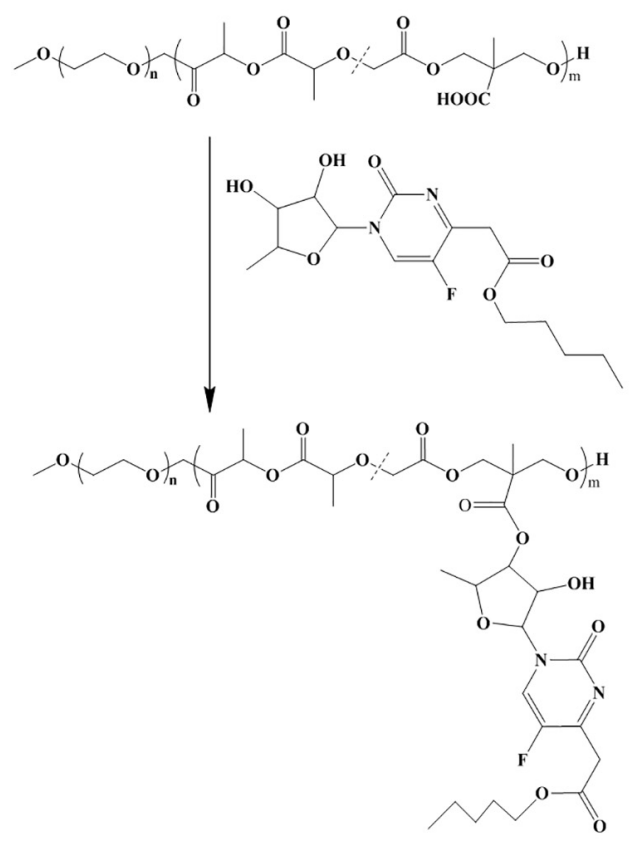

PEG-PLA/Capecitabine Conjugates
B
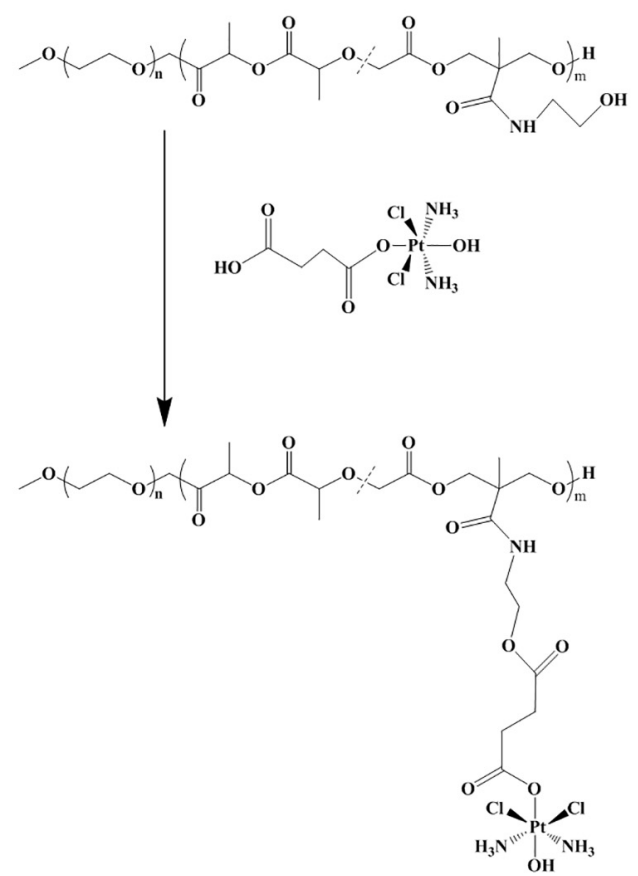

PEG-PLA/CisPt(IV) Conjugates

SCHEME 1 | Synthesis of (A) PEG-PLA/capecitabine conjugates and (B) PEG-PLA/CisPt(IV) conjugates.

$0.625 \mathrm{mmol}$ ), NHS (71.9 mg, $0.625 \mathrm{mmol}$ ), and DMAP (76.35 mg, $0.625 \mathrm{mmol}$ ) were added. The reaction mixture was constantly stirred in an ice bath for $24 \mathrm{~h}$. Next, it was filtered to remove 1,3dicyclohexylurea (DCU). The filtrate was then added dropwise to cold diethyl ether $(50 \mathrm{~mL})$, the resultant precipitate was collected by filtration and dried under vacuum to obtain the NHS ester of MPEG- $b$-P(LA-co-MCC).

\section{Synthesis of MPEG-b-P(LA-co-MCC)-OH}

The NHS ester of MPEG- $b$-P(LA-co-MCC) $(0.5 \mathrm{~g}, 0.0625 \mathrm{mmol})$ was dissolved in dried $\mathrm{CH}_{2} \mathrm{Cl}_{2}$ and 2-aminoethyl alcohol $(4.6 \mathrm{mg}$, $0.075 \mathrm{mmol}$ ) was added to the polymer solution. The reaction mixture was stirred at room temperature for $24 \mathrm{~h}$ and then precipitated with ether to obtain the final product MPEG- $b$ $\mathrm{P}(\mathrm{LA}-\mathrm{co}-\mathrm{MCC})-\mathrm{OH}$.

\section{Synthesis of MPEG-b-P(LA-co-MCC)-OH/Pt(IV) Conjugates}

Cisplatin(IV)-COOH [abbreviated as CisPt(IV)] was synthesized as described previously. CisPt(IV) was conjugated to the polymer MPEG- $b$-P(LA-co-MCC)-OH with pendant hydroxyl groups using N-dicyclohexyl carbodiimide/4-dimethylaminopyridine (DCC/DMAP). Briefly, CisPt(IV) (43.3 mg, $0.081 \mathrm{mmol}$ ) was first dissolved in dried N,N-Dimethylformamide (DMF) $(1 \mathrm{~mL})$ in a flask under stirring conditions. The polymer MPEG- $b$-P(LAco-MCC)-OH (0.5 g, $0.0625 \mathrm{mmol})$ was then dissolved in $3 \mathrm{~mL}$ of $\mathrm{C}_{2} \mathrm{H}_{2} \mathrm{Cl}_{2}$ and then added to the CisPt(IV) solution. Next,
$128.9 \mathrm{mg}$ of DCC, $76.35 \mathrm{mg}$ of DMAP and $95.7 \mathrm{mg}$ of HOBt were added into the solution. The reaction mixture was stirred for 2 days at room temperature. Afterward, the mixture was filtered to remove DCU. The filtrate was slowly added to diethyl ether to precipitate the crude product, which was then dried to yield a pale yellow powder. Next, the powder was dissolved in DMF and placed into a dialysis bag and dialyzed against water to remove unreacted $\mathrm{Cis} \mathrm{Pt}(\mathrm{IV})$. Finally, the solution was lyophilized to obtain the MPEG- $b$-P(LA-co-MCC)-OH/Pt(IV) conjugates.

\section{Synthesis of MPEG-b-P(LA-co-MCC)/Capecitabine Conjugates}

Capecitabine was conjugated to the polymer MPEG- $b$ $\mathrm{P}$ (LA-co-MCC) with pendant carboxyl groups using the DCC/DMAP/HOBt method. Briefly, capecitabine $(43.3 \mathrm{mg}$, $0.081 \mathrm{mmol}$ ) was first dissolved in dried DMSO in a flask under stirring conditions and $0.5 \mathrm{~g}$ MPEG- $b$-P(LA-co-MCC) dissolved in $3 \mathrm{~mL}$ of $\mathrm{C}_{2} \mathrm{H}_{2} \mathrm{Cl}_{2}$ was then added. Afterward, $128.9 \mathrm{mg}$ of DCC, $76.35 \mathrm{mg}$ of DMAP, and $95.7 \mathrm{mg}$ of HOBt were added. The reaction mixture was stirred for 2 days at room temperature. Next, it was filtered to remove DCU, precipitated by ether and collected by filtration. The product was dried to obtain a red powder. The powder was then dissolved in DMF and it was placed into a dialysis bag and dialyzed against water to remove unreacted capecitabine. Finally, following the dialysis, the solution was lyophilized to yield the MPEG- $b$-P(LA-co-MCC)/capecitabine conjugates. 

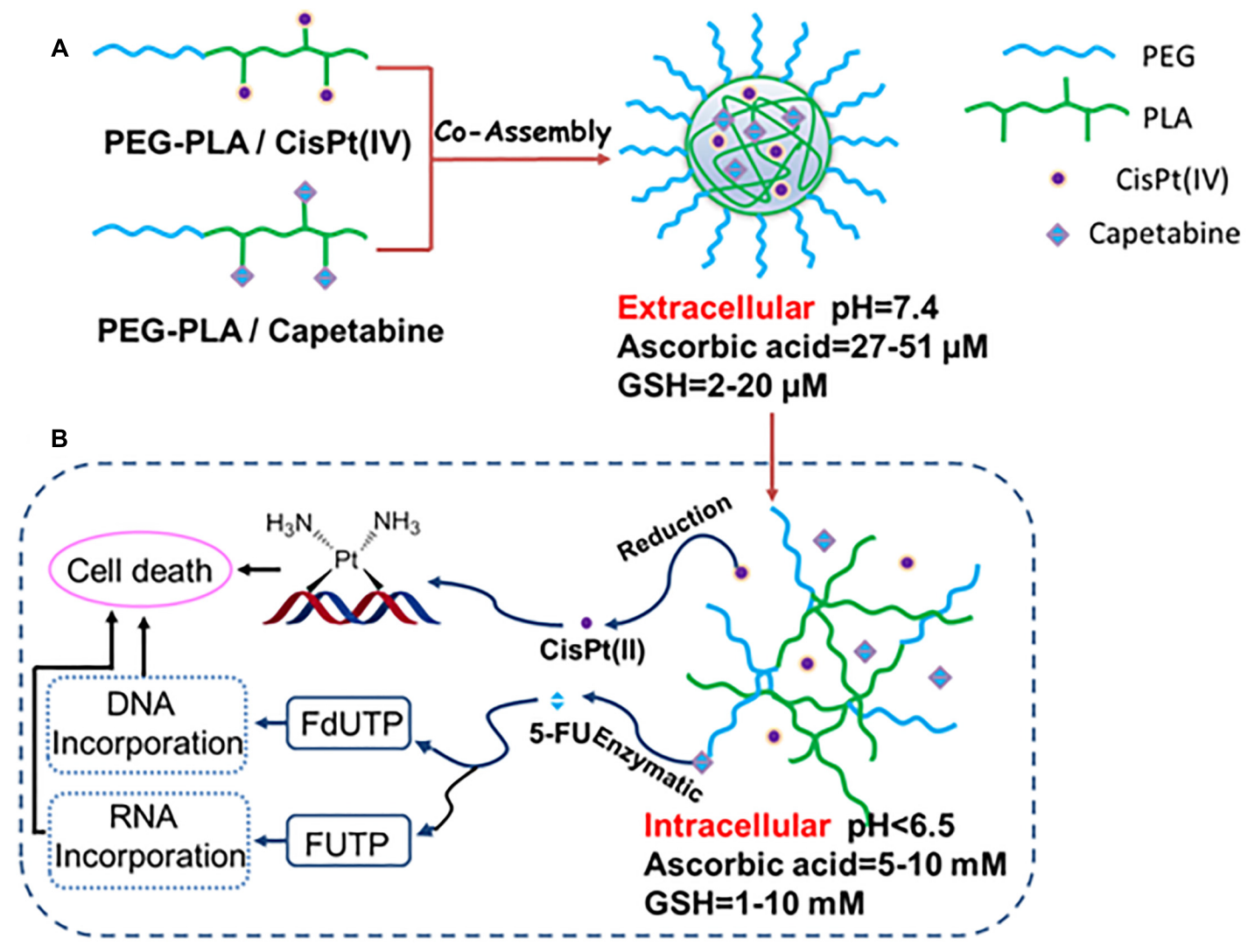

SCHEME 2 | (A) Preparation of drug combination micelles and (B) a schematic representation of hypothetical cellular pathways and mechanism of action of drug combination micelles.

\section{Preparation of MPEG- $b$-P(LA-co-MCC)- $\mathrm{OH} / \mathrm{Pt}(\mathrm{IV})$ and MPEG-b-P(LA-co-MCC)/ Capecitabine CM}

The CM were prepared by nano-precipitation method. In brief, $50 \mathrm{mg}$ of MPEG- $b$-P(LA-co-MCC)-OH/Pt(IV) conjugates and $50 \mathrm{mg}$ of MPEG- $b$-P(LA-co-MCC)/capecitabine conjugates were dissolved in a flask filled with $10 \mathrm{~mL}$ of DMF. Next, the solution was added in a dropwise fashion into the flask under stirring to form a micellar solution. The solution was then dialyzed against water to remove DMF and then freeze-dried to obtain the MPEG- $b$-P(LA-co-MCC)-OH/Pt(IV) and MPEG- $b$-P(LA- $c o-$ $\mathrm{MCC})$ /capecitabine CM.

\section{In vitro Drug Release of CM}

The CM (5 mg) were dissolved in PBS (10 mL, $0.1 \mathrm{M}, \mathrm{pH}$ 7.4, or $\mathrm{pH} 5.5)$ and then placed into a pre-swelled dialysis bag (3500 MWCO), which was immersed into PBS $(100 \mathrm{~mL})$ at $37^{\circ} \mathrm{C}$ in a shaking culture incubator (Wang et al., 2012). At $1 \mathrm{~h}$ intervals, $1.5 \mathrm{~mL}$ of sample solution was withdrawn from the dialysate and measured for the Pt and capecitabine concentration using ICP-OES and HPLC, respectively. After sampling, fresh PBS $(1.5 \mathrm{~mL})$ was immediately added back into the incubation medium. The process was repeated for $8 \mathrm{~h}$. The Pt released from the micelles was expressed as the percentage of the cumulative
Pt or capecitabine outside the dialysis bag to the total Pt or capecitabine inside the micelles.

\section{Cell Lines and Cell Culture Conditions}

Human Colorectal Tumor Cells HCT-8 (ATCC) were cultured in RPMI 1640 media (Hyclone, Logan, UT, United States) supplemented with $10 \%$ fetal bovine serum (FBS, Life Technologies, United States), $100 \mathrm{U} / \mathrm{mL}$ penicillin and $100 \mu \mathrm{g} / \mathrm{mL}$ streptomycin (Ameresco, Life Technologies, United States) at $37^{\circ} \mathrm{C}$ with $5 \% \mathrm{CO}_{2}$.

\section{Cell Viability Studies}

The HCT- 8 cells harvested in a logarithmic growth phase were seeded in 96-well plates at a density of $1 \times 10^{4}$ cells/well and incubated in $100 \mu \mathrm{L} /$ well RPMI 1640 medium for $12 \mathrm{~h}$. The medium was then replaced by $\mathrm{CM}$ with a $\mathrm{Pt}$ concentration ranging from 0.1 to $432 \mu \mathrm{M}$. To assess cell viability, $20 \mu \mathrm{L}$ of MTT solution $(5 \mathrm{mg} / \mathrm{mL}$ ) was added and the plates were incubated for another $4 \mathrm{~h}$ at $37^{\circ} \mathrm{C}$. Next, the culture medium containing MTT was removed and $150 \mu \mathrm{L}$ of DMSO was added to dissolve the formazan crystals that were formed. Finally, the plates were shaken for $10 \mathrm{~min}$ and the absorbance was measured at $492 \mathrm{~nm}$ using a microplate reader. 


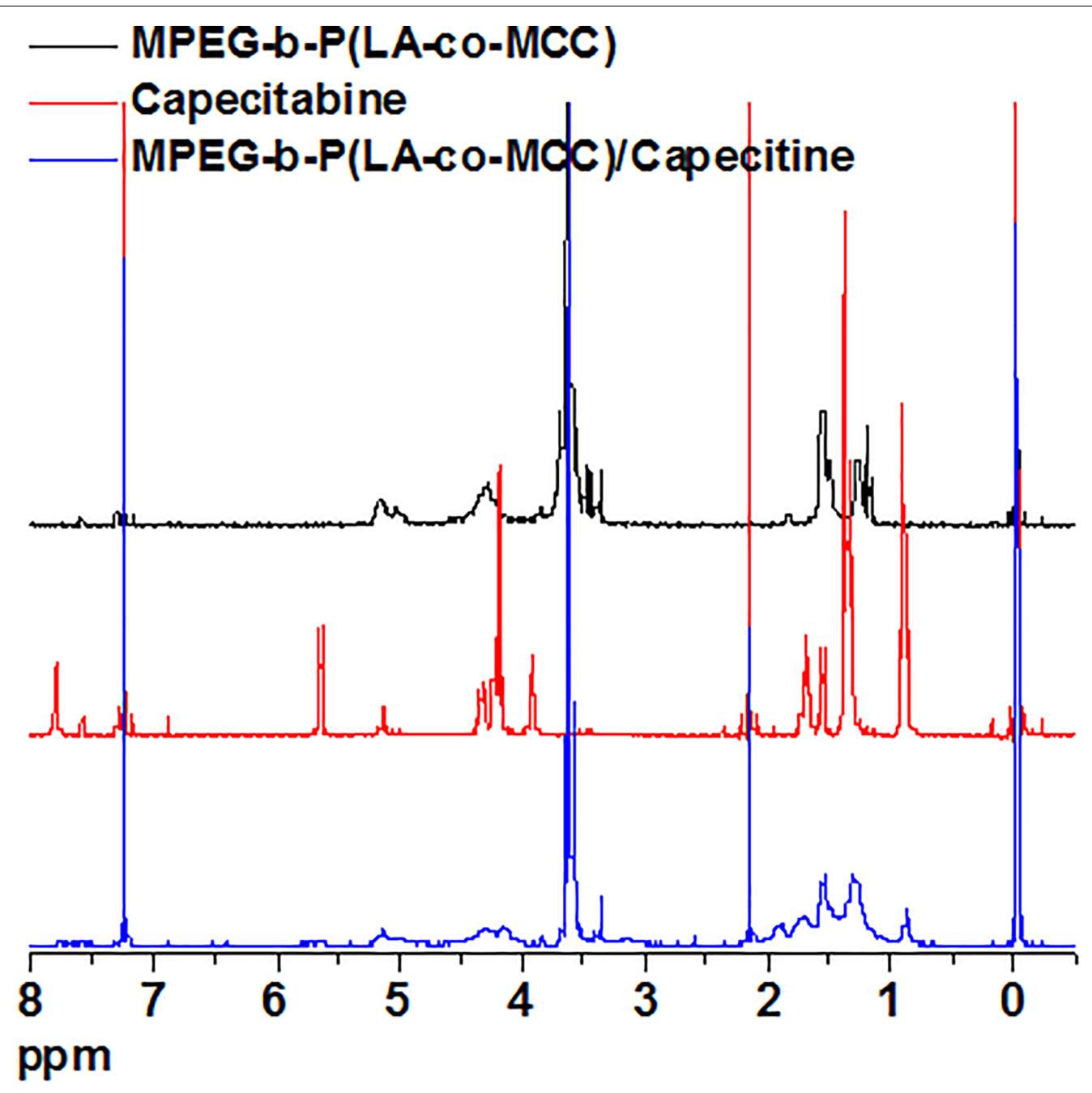

FIGURE 1 | The ${ }^{1} \mathrm{H}-\mathrm{NMR}$ spectra of MPEG- $b-\mathrm{P}(\mathrm{LA}-\mathrm{CO}-\mathrm{MCC})$ (black curve), capecitabine (red curve), and MPEG- $b-\mathrm{P}(\mathrm{LA}-\mathrm{co}-\mathrm{MCC}) / \mathrm{capecitabine}$ (blue curve).
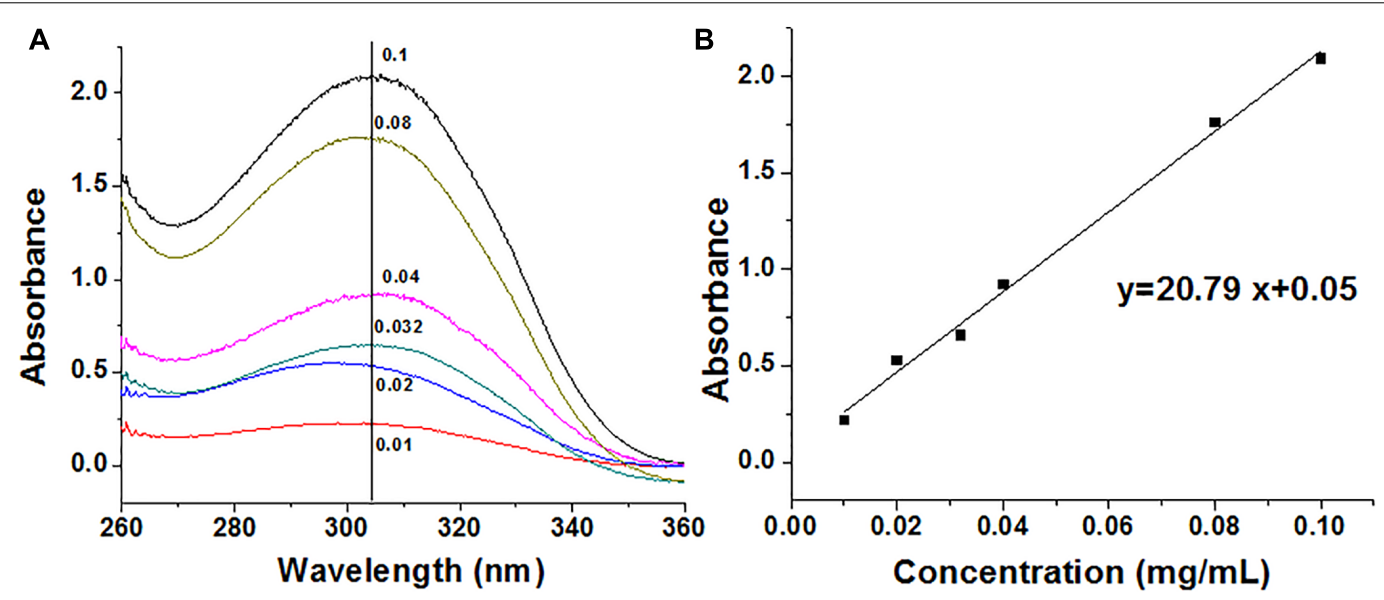

FIGURE 2 | Determination of the capecitabine content in drug combination particles. (A) UV-vis spectra of stock solutions of capecitabine in water (mg/mL) and (B) standard curve of capecitabine stock solutions. 


\section{Synthesis of}

\section{MPEG-b-P(LA-co-MCC)-OH/CisPt(IV)}

\section{Conjugates}

With CisPt(IV) in hand, we hoped to create a carrier polymer with hydroxyl groups. Therefore, MPEG- $b$-P(LA-co-MCC)-OH was synthesized according to our previous report (Xiao et al., 2012). CisPt(IV) was conjugated to the polymer MPEG- $b$ $\mathrm{P}$ (LA-co-MCC)-OH using DCC/DMAP method and the ICPOES measurement of MPEG- $b$-P(LA-co-MCC)-OH/CisPt(IV) conjugates indicated a Pt content of $9.3 \mathrm{w} / \mathrm{w} \%$.

\section{Synthesis and Characterization of MPEG-b-P(LA-co-MCC)/Capecitabine Conjugates}

Capecitabine was conjugated to the polymer MPEG- $b$-P(LA-coMCC) with pendant carboxyl groups using the DCC/DMAP/ HOBt method. The ${ }^{1} \mathrm{H}-\mathrm{NMR}$ spectra of capecitabine, MPEG$b$-P(LA-co-MCC) and MPEG- $b-\mathrm{P}(\mathrm{LA}-c o-\mathrm{MCC}) /$ capecitabine in deuterated chloroform $\left(\mathrm{CDCl}_{3}\right)$ solvent were collected and are summarized in Figure 1. Compared to the ${ }^{1} \mathrm{H}-\mathrm{NMR}$ spectrum of MPEG- $b$-P(LA-co-MCC), we identified additional new peaks in the MPEG- $b$-P(LA-co-MCC)/capecitabine conjugates. These peaks may likely be attributed to capecitabine. Moreover, we collected the UV-vis spectra of capecitabine solutions at different concentrations $(0.01-0.1 \mathrm{mg} / \mathrm{mL})$ and summarized the data in Figure 2A. Using the spectra, we were able to calculate the standard curve of absorbance at $304 \mathrm{~nm}$ vs. capecitabine concentration (Figure 2B). This standard curve and the UVvis spectra of MPEG- $b$-P(LA-co-MCC)/capecitabine conjugates revealed that the capecitabine content in the conjugates was $17 \% \mathrm{w} / \mathrm{w}$.

\section{Preparation of the Mixed Polymer-Drug Micelles}

Drug combination particles were prepared by the self-assembly method. The obtained particles were spherical micelles with a mean diameter of $55 \mathrm{~nm}$ (according to TEM) and $110 \mathrm{~nm}$
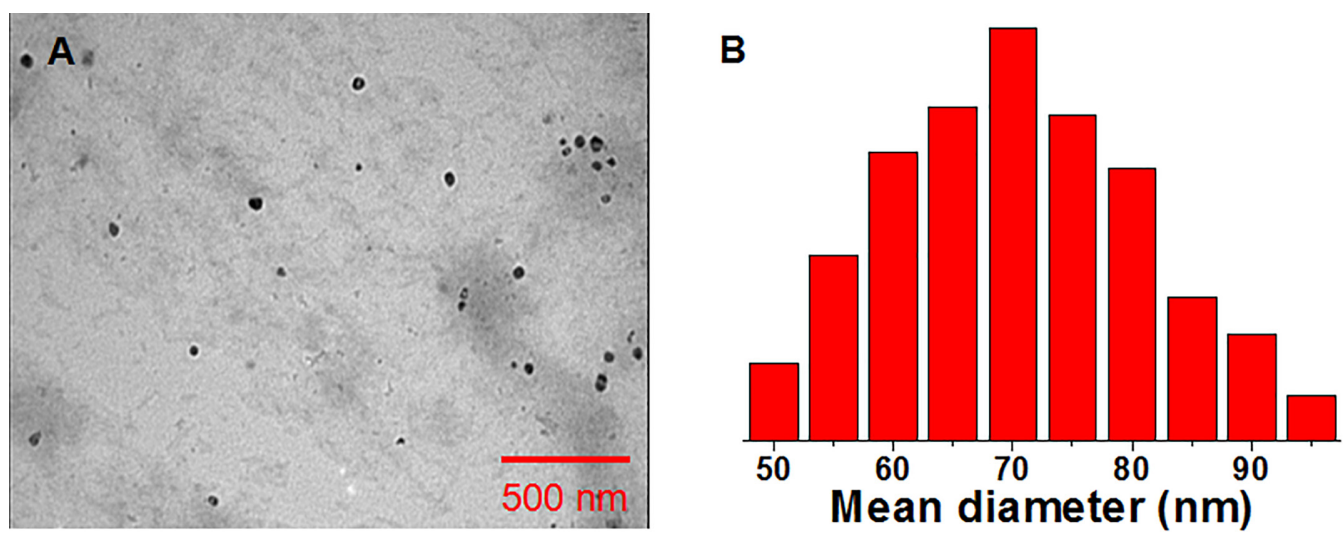

FIGURE 3 | (A) TEM and (B) DLS characterization of the drug combination particles.

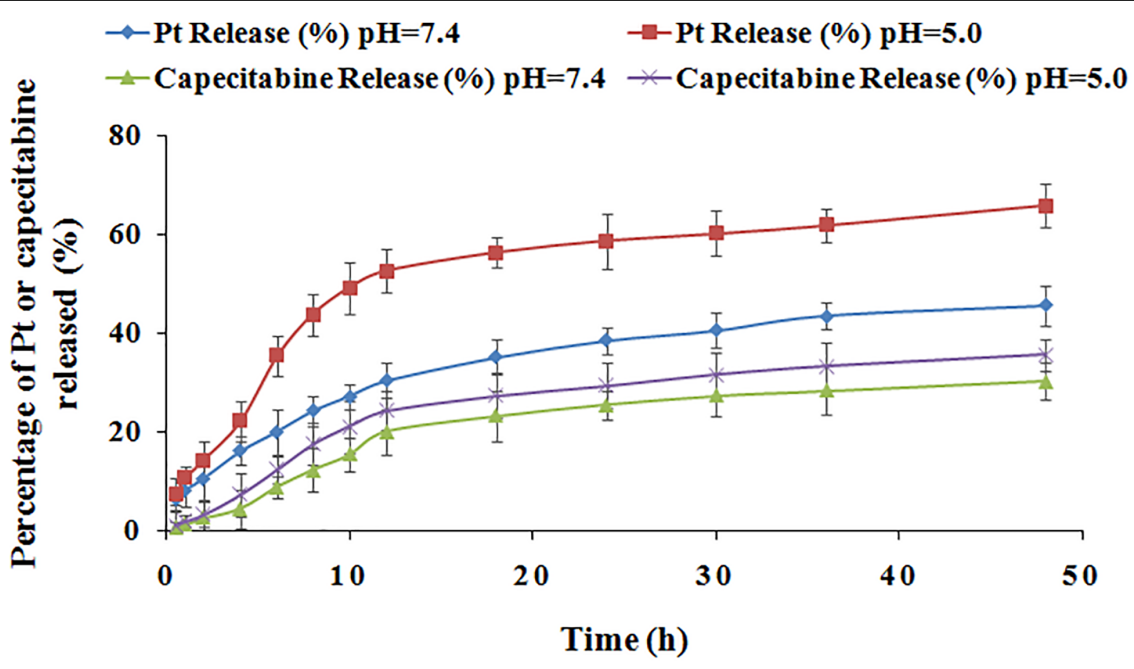

FIGURE 4 | Pt and capecitabine release profiles in buffer solutions at $\mathrm{pH} 5.0$ and $\mathrm{pH} 7.4$. 
TABLE 1 | The IC50 values of free drug CPT/CisPt(II) combinations and mixed polymer-drug micelles M[CPT/CisPt(II)] with various CPT/CisPt(II) ratios evaluated in HCT-8 cells at $48 \mathrm{~h}$.

\begin{tabular}{lccc}
$\begin{array}{l}\text { Free drug } \\
\text { combinations }\end{array}$ & $\mathbf{I C}_{\mathbf{5 0}}(\boldsymbol{\mu} \mathbf{m o l} / \mathbf{L})$ & Polymer-drug Micelles & $\mathbf{I C}_{\mathbf{5 0}}(\boldsymbol{\mu} \mathbf{~ m o l} / \mathbf{L})$ \\
\hline $\mathrm{CisPt}(\mathrm{II})$ & 13.66 & $\mathrm{M}[\mathrm{CisPt}(\mathrm{II})]$ & 21.47 \\
$\mathrm{CPT}_{0.1} / \mathrm{Pt}$ & 9.62 & $\mathrm{M}\left(\mathrm{CPT}_{0.1} / \mathrm{Pt}\right)$ & 13.82 \\
$\mathrm{CPT}_{0.2} / \mathrm{Pt}$ & 7.74 & $\mathrm{M}\left(\mathrm{CPT}_{0.2} / \mathrm{Pt}\right)$ & 11.55 \\
$\mathrm{CPT}_{0.5} / \mathrm{Pt}$ & 5.03 & $\mathrm{M}\left(\mathrm{CPT}_{0.5} / \mathrm{Pt}\right)$ & 7.40 \\
\hline
\end{tabular}

(according to DLS) (Figure 3). The resulting particle size using the DLS was larger compared to the TEM assessment, likely due to the shrinkage during the TEM sample preparation process.
The particles displayed a zeta potential of $-4.4 \mathrm{mV}$, which is almost neutral, hence we expected the particles to have a good stability in vivo.

\section{RESULTS AND DISCUSSION \\ Drug Release}

Drug release experiments were performed at different $\mathrm{pH}$ values as stated in the literature (Choi et al., 1998). Data presented in Figure 4 show the release kinetics $(0-50 \mathrm{~h})$ for $\mathrm{Pt}$ and capecitabine in the combination drugs in two conditions at $\mathrm{pH}$ 5.0 and $\mathrm{pH}$ 7.4. Overall, the drug release curves showed that the two drugs displayed sustained release at both $\mathrm{pH} 5.0$ and

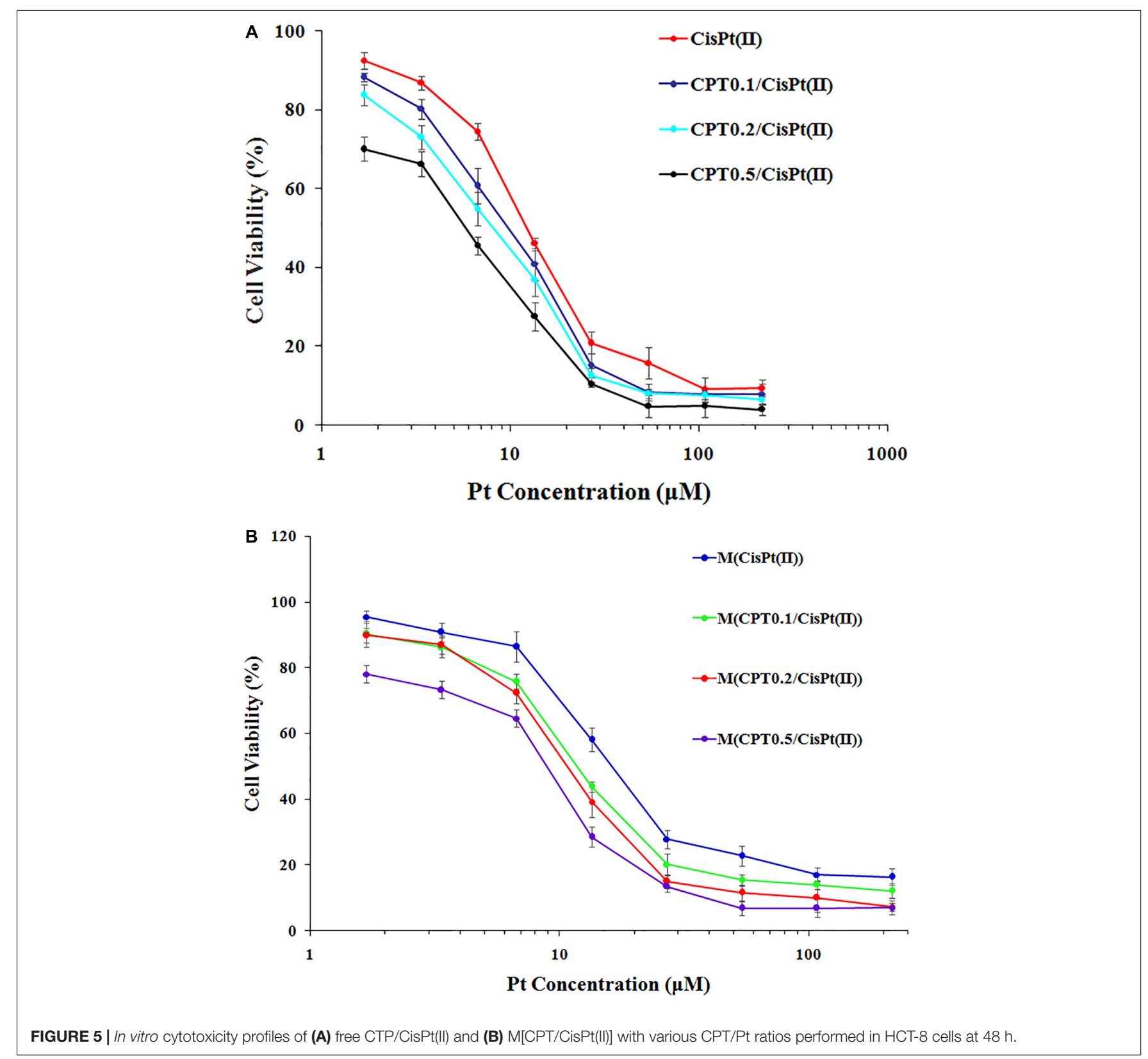


$\mathrm{pH} 7.0$ and the maximum release occurred at approximately $12 \mathrm{~h}$ and then remained stable for $50 \mathrm{~h}$. Moreover, the cumulative release percentages of $\mathrm{Pt}$ and capecitabine at $\mathrm{pH} 5.0$ were higher compared to values at $\mathrm{pH}$ 7.4. Additionally, we observed that the $\mathrm{Pt}$ release was more sensitive to $\mathrm{pH}$ compared to the capecitabine release. Importantly, the intracellular compartments for the endosomes and lysosomes are acidic in cancer cells, allowing for the release of these two drugs into cancer cells and thereby improving the therapeutic effect.

\section{In vitro Cytotoxicity}

We calculated the $\mathrm{IC}_{50}$ values of the combination therapy of free drug capecitabine(CPT)/CisPt(II) combinations and mixed polymer-drug micelles $\mathrm{M}(\mathrm{CPT} / \mathrm{CisPt}(\mathrm{II}))$ with various $\mathrm{CPT} / \mathrm{CisPt}(\mathrm{II})$ ratios in HCT-8 cells at $48 \mathrm{~h}$ (Table $\mathbf{1}$ ). We observed that both free drugs $\mathrm{CPT} / \mathrm{CisPt}$ and mixed polymerdrug micelles $\mathrm{M}[\mathrm{CPT} / \mathrm{CisPt}(\mathrm{II})]$ exhibited an enhancement of combination potency accompanied by dose-response profiles being shifted toward lower drug concentrations when the CPT/Pt molar ratio increased (Figure 5).

At $48 \mathrm{~h}$, the $\mathrm{IC}_{50}$ values of free $\mathrm{CisPt}(\mathrm{II})$ alone and $\mathrm{M}[\mathrm{CisPt}(\mathrm{II})]$ were 13.66 and $21.47 \mu \mathrm{M}$, respectively. The $\mathrm{IC}_{50}$ values of both free drug combinations and the polymerdrug micelles were sharply reduced when the CPT/Pt molar ratio increased (Table $\mathbf{1}$ ). These data suggest that synergistic cytotoxicity of CPT/CisPt(II) formulations against HCT-8 cells was evident. More importantly, the mixed polymer-drug micelles, $\mathrm{M}[\mathrm{CPT} / \mathrm{CisPt}(\mathrm{II})]$, had similar synergistic effects in HCT-8 cells. In short, $\mathrm{M}(\mathrm{PTX} / \mathrm{Pt}$ ) (PTX is short for paclitaxel) displayed significant time- and dose-dependent inhibitory effects allowing for the dissociation and the release of the drugs into the cells.

\section{CONCLUSION}

In this study, we successfully created a synthetic strategy for drug co-delivery by conjugating and co-assembling, wherein

\section{REFERENCES}

Ahmad, S. (2010). Platinum-DNA interactions and subsequent cellular processes controlling sensitivity to anticancer platinum complexes. Chem. Biodivers. 7, 543-566. doi: 10.1002/cbdv.200800340

Arkenau, H. T., Bermann, A., Rettig, K., Strohmeyer, G., and Porschen, R. (2003). 5 Fluorouracil plus leucovorin is an effective adjuvant chemotherapy in curatively resected stage III colon cancer: long-term follow-up results of the adjCCA-01 trial. Ann. Oncol. 14, 395-399. doi: 10.1093/annonc/mdg100

Bae, Y. H., and Park, K. (2011). Targeted drug delivery to tumors: myths, reality and possibility. J. Control. Release 153, 198-205. doi: 10.1016/j.jconrel.2011. 06.001

Boulikas, T., Pantos, A., Bellis, E., and Christofis, P. (2007). Designing platinum compounds in cancer: structures and mechanisms. Cancer Ther. 5, 537-583. doi: 10.1016/j.jinorgbio.2014.07.011

Choi, S., Filotto, C., Bisanzo, M., Delaney, S., Lagasee, D., Whitworth, J. L., et al. (1998). Reduction and anticancer activity of platinum(IV) complexes. Inorg. Chem. 37, 2500-2504. doi: 10.1021/ic971047x

Di Francesco, M., Ruggiero, A., and Riccardi, R. (2002). Cellular and molecular aspects of drugs of the future: oxaliplatin. Cell. Mol. Life Sci. 59, 1914-1927. doi: 10.1007/PL00012514 two different drugs, including CisPt(II) based drugs, are enveloped into one carrier polymer allowing for the delivery of the combination therapy. Our method exhibited effective synergistic effect in vitro between the free CTP/CisPt(II) and the composite $\mathrm{M}(\mathrm{PTX} / \mathrm{Pt})$ micelles. Furthermore, the polymer-based combination of capecitabine and cisplatin(IV) prodrug displayed safer and more efficacious inhibition of HCT-8 cell growth compared to the small molecules individually. We hope that our combination strategy can be extended to other anticancer drugs. Given the significant effect of the combination therapy, we believe this strategy will likely be utilized in the clinic in the foreseeable future.

\section{AUTHOR CONTRIBUTIONS}

LL, GC, and WL designed the experiments. XX and TW carried out the experiments and wrote the manuscript. $\mathrm{ZZ}$ and $\mathrm{WZ}$ helped analyzing the experimental results.

\section{FUNDING}

This work was supported by the Keypoint Research and Invention Program (No. AWS17J016), the National Natural Science Foundation of China (Grant No. 21871246), the Grant of Jilin Province Science and Technology Committee (Nos. 20180101194JC, 20170520149JH, and 20180520009JH), Jilin Province Science and Technology project of traditional Chinese medicine (2017103), Jilin Province Education Department the Science and Technology development project (Nos. JJKH20181117KJ and JJKH 20191059KJ), the Youth Foundation project of Jilin Province Health and Family Planning Commission (No. 2016Q053), the Science and Technology Key Project of Henan Province (182102310611), and National College Student Innovation Training Program (201713743002).

DÍaz-Rubio, E., Evans, T. R. J., Tabernero, J., Cassidy, J., Sastre, J., Eatock, M., et al. (2002). Capecitabine (Xeloda ${ }^{\circledR}$ ) in combination with oxaliplatin: a phase I, dose-escalation study in patients with advanced or metastatic solid tumors. Ann. Oncol. 13, 558-565. doi: 10.1093/annonc/mdf065

Duncan, R. (2003). The dawning era of polymer therapeutics. Nat. Rev. Drug Discov. 2, 347-360. doi: 10.1038/nrd1088

Ekborn, A., Laurell, G., Andersson, A., Wallin, I., Eksborg, S., and Ehrsson, H. (2000). Cisplatin-induced hearing loss: influence of the mode of drug administration in the guinea pig. Hear. Res. 140, 38-44. doi: 10.1016/S03785955(99)00190-2

Feldmann, G., Dhara, S., Fendrich, V., Bedja, D., Beaty, R., and Mullendore, M. (2007). Blockade of hedgehog signaling inhibits pancreatic cancer invasion and metastases: a new paradigm for combination therapy in solid cancers. Cancer Res. 67, 2187-2196. doi: 10.1158/0008-5472.CAN-06-3281

Jamieson, E. R., and Lippard, S. J. (1999). Structure, recognition, and processing of cisplatin-DNA adducts. Chem. Rev. 99, 2467-2498. doi: 10.1021/cr980421n

Joensuu, H., Holli, K., Heikkinen, M., Suonio, E., Aro, A. R., Hietanen, P., et al. (1998). Combination chemotherapy versus single-agent therapy as first- and second-line treatment in metastatic breast cancer: a prospective randomized trial. J. Clin. Oncol. 16, 3720-3730. doi: 10.1200/JCO.1998.16.12. 3720 
Kwangjae, C., Wang, X., Nie, S. M., Chen, Z., and Shin, D. M. (2008). Clin. Cancer Res. 14, 1310-1316. doi: 10.1158/1078-0432.CCR-07-1441

Lebwohl, D., and Canetta, R. (1998). Clinical development of platinum complexes in cancer therapy: an historical perspective and an update. Eur. Cancer J. 34, 1522-1534. doi: 10.1016/S0959-8049(98)00224-X

Ling, X., Tu, J. S., Wang, J. Q., Shajii, A., Kong, N., Feng, C., et al. (2019). Glutathione-responsive prodrug nanoparticles for effective drug delivery and cancer therapy. ACS Nano 13, 357-370. doi: 10.1021/acsnano.8b06400

Love, R. R., Leventhal, H., Easterling, D. V., and Nerenz, D. R. (1989). Side effects and emotional distress during cancer chemotherapy. Cancer 63, 604612. doi: 10.1002/1097-0142(19890201)63:3<604::AID-CNCR2820630334>3.0. $\mathrm{CO} ; 2-2$

Madias, N. E., and Harrington, J. T. (1978). Platinum nephrotoxicity. Am. J. Med. 65, 307-314. doi: 10.1016/0002-9343(78)90825-2

Maeda, H. (2010). Tumor-selective delivery of macromolecular drugs via the EPR effect: background and future prospects. Bioconjug. Chem. 21, 797-802. doi: $10.1021 / \mathrm{bc} 100070 \mathrm{~g}$

Pasettoa, L. M., Andreab, M. R., Brandesa, A. A., Rossia, E., and Monfardinia, S. (2006). The development of platinum compounds and their possible combination. Crit. Rev. Oncol. Hemat. 60, 59-75. doi: 10.1016/j.critrevonc.2006. 02.003

Rosenberg, B., and Lippert, B. (eds) (1999). Cisplatin: Chemistry and Biochemistry of a Leading Anticancer Drug. New York: Wiley-VCH.

Sharma, R., Tobin, P., and Clarke, S. J. (2005). Management of chemotherapyinduced nausea, vomiting, oral mucositis, and diarrhea. Lancet Oncol. 6, 93-102. doi: 10.1016/S1470-2045(05)01735-3

Shen, J., Zhu, Y., Shi, H. D., and Liu, Y. Z. (2018). Multifunctional nanodrug delivery systems for platinum-based anticancer drugs. Prog. Chem. 30, 15571572.

Sitzia, J., and Huggins, L. (1998). Side effects of cyclophosphamide, methotrexate, and 5-fluorouracil (CMF) chemotherapy for breast cancer. Cancer Pract. 6, 13-21. doi: 10.1046/j.1523-5394.1998.1998006013.x

Ssif, M. W., Katirtzoglou, N. A., and Syrigos, K. N. (2008). Capecitabine: an overview of the side effects and their management. Anti Cancer Drug 19, 447-464. doi: 10.1097/CAD.0b013e3282f945aa

Tao, W., Ji, X. Y., Zhu, X. B., Li, L., Wang, J. Q., Zhang, Y., et al. (2018). Two-dimensional antimonene-based photonic nanomedicine for cancer theranostics. Adv. Mater. 30, 1802061-1802072. doi: 10.1002/adma.201802061

Tao, W., Li, X. Y., Xu, X. D., Islam, M. A., Li, Z. J., Chen, S., et al. (2017). Antimonene quantum dots: synthesis and application as near-infrared photothermal agents for effective cancer therapy. Angew. Chem. Int. Ed. 56, 11896-11900. doi: 10.1002/anie.201703657

Tao, W., Zeng, X. W., Liu, T., Wang, Z. Y., Xiong, Q. Q., Ouyang, C. P., et al. (2013). Docetaxel-loaded nanoparticles based on star-shaped mannitol-core
PLGA-TPGS diblock copolymer for breast cancer therapy. Acta Biomater. 9, 8910-8920. doi: 10.1016/j.actbio.2013.06.034

Tao, W., Zeng, X. W., Wu, J., Zhu, X., Yu, X. H., Zhang, X. D., et al. (2016). Polydopamine-based surface modification of novel nanoparticleaptamer bioconjugates for $\backslash \mathrm{r}$ in vivo $\backslash \mathrm{r}$ breast cancer targeting and enhanced therapeutic effects. Theranostics 6, 470-484. doi: 10.7150/thno.14184

Tao, W., Zeng, X. W., Zhang, J. X., Zhu, H. J., Chang, D. F., Zhang, X. D., et al. (2014). Synthesis of cholic acid-core poly( $\varepsilon$-caprolactone-ran-lactide)b-poly(ethylene glycol) 1000 random copolymer as a chemotherapeutic nanocarrier for liver cancer treatment. Biomater. Sci. 2, 1262-1274. doi: 10. 1039/C4BM00134F

Wang, R., Xiao, H. H., Song, H. Q., Zhang, Y., Hu, X. L., Xie, Z. G., et al. (2012). Co-delivery of all-trans-retinoic-acid and cisplatin(IV) prodrug based on polymer-drug conjugates for enhanced efficacy and safety. J. Mater. Chem. 22, 25453-25462. doi: 10.1039/c2jm35232j

Weiss, R. B., and Christian, M. C. (1993). New cisplatin analogues in development. A review. Drugs 46, 360-377. doi: 10.2165/00003495-199346030-00003

Windebank, A. J., and Grisold, W. (2008). Chemotherapy-induced neuropathy. J. Peripher. Nerv. Syst. 13, 27-46. doi: 10.1111/j.1529-8027.2008. 00156.x

Woodcock, J., Griffin, J. P., and Behrman, R. E. (2011). Development of novel combination therapies. N. Engl. J. Med. 364, 985-987. doi: 10.1056/ NEJMp1101548

Xiao, H. H., Qi, R. G., Li, T., Awuah, S. G., Zheng, Y. R., Wei, W., et al. (2017). Maximizing synergistic activity when combining RNAi and platinum-based anticancer agents. J. Am. Chem. Soc. 139, 3033-3044. doi: 10.1021/jacs.6b12108

Xiao, H. H., Yan, L. S., Zhang, Y., Qi, R. G., Li, W. L., Wang, R., et al. (2012). A dualtargeting hybrid platinum(IV) prodrug for enhancing efficacy. Chem. Commun 48, 10730-10732. doi: 10.1039/c2cc34297a

Zhu, X. B., Ji, X. Y., Kong, N., Chen, Y. H., Mahmoudi, M., Xu, X. D., et al. (2018). Intracellular mechanistic understanding of 2D MoS2 nanosheets for anti-exocytosis-enhanced synergistic cancer therapy. ACS Nano 12, 2922-2938. doi: 10.1021/acsnano.8b00516

Conflict of Interest Statement: The authors declare that the research was conducted in the absence of any commercial or financial relationships that could be construed as a potential conflict of interest.

Copyright (๑) 2019 Xiao, Wang, Li, Zhu, Zhang, Cui and Li. This is an open-access article distributed under the terms of the Creative Commons Attribution License (CC BY). The use, distribution or reproduction in other forums is permitted, provided the original author(s) and the copyright owner(s) are credited and that the original publication in this journal is cited, in accordance with accepted academic practice. No use, distribution or reproduction is permitted which does not comply with these terms. 